\title{
Ammonia Oxidation at High Pressure as a Carbon Free Fuel
}

\author{
Pedro García Ruiz, María Abián, Uxue Alzueta \\ Aragón Institute of Engineering Research (I3A), Department of Chemical and Environmental Engineering \\ Universidad de Zaragoza, Mariano Esquillor s/n, 50018, Zaragoza, Spain. \\ Tel. +34-976762707, e-mail: p.garcia@unizar.es
}

\begin{abstract}
Ammonia can be burned directly without pollutant emissions. Its mixtures with $\mathrm{CH}_{4}$ and $\mathrm{H}_{2}$ improve its combustion characteristics. Therefore, the project thesis is the knowledge of the conversion at high pressures of $\mathrm{NH}_{3}$ and its mixtures as well as the development of a suitable kinetic model.
\end{abstract}

\section{Introduction}

Low-carbon economy has a critical role in environmental issues of our society, such as climate change, security of energy supply and fossil fuels depletion. The principal aim is to reduce greenhouse gas emissions, which implies the use of carbon-free fuels, and guaranteeing security of energy supply.

$\mathrm{NH}_{3}$ contributes to this objective because it can be a suitable alternative for stationary power, transportation, and energy storage[1]. Although it is mainly produced from natural gas, it can also be obtained using renewable energy sources and raw materials.

In addition, $\mathrm{NH}_{3}$ can be used as a clean energy carrier because it can be burned directly[2] producing water and nitrogen $\left(\mathrm{N}_{2}\right)$. As a disadvantage, in the $\mathrm{NH}_{3}$ combustion, nitrogen oxides $\left(\mathrm{NO}_{\mathrm{x}}\right)$ can be formed from $\mathrm{NH}_{3}$ oxidation, but also the join presence of $\mathrm{NH}_{3}$ and $\mathrm{NO}$ in the combustion chamber can result in the joint minimization of both if appropriate operating conditions are used[3].

Another aspect to be considered is its relatively poor combustion characteristics, which justifies the cocombustion of $\mathrm{NH}_{3}$ with other fuels such as $\mathrm{CH}_{4}$ and $\mathrm{H}_{2}[4]$.

In this context, the overall objective of the project thesis is the knowledge of the conversion of $\mathrm{NH}_{3}$ at high pressures, as well as its mixtures with $\mathrm{CH}_{4}$ and $\mathrm{H}_{2}$ under different operating conditions (temperature, air excess rate, concentration of ammonia and NO presence). To this end, this project will also include the development of a detailed reaction kinetic model in order to describe the conversion of ammonia and its mixtures under the studied conditions. This project thesis will contribute to evaluating the pollutant emissions that can be obtained during the use of ammonia in energy applications and determining the possible synergies due to the interaction of $\mathrm{NH}_{3}$ and its mixtures with $\mathrm{NO}$, which can result in a further reduction of this compound.

\section{Experimental and modelling methodology}

Conversion of reactants and gas emissions produced from combustion of $\mathrm{NH}_{3}$, and its mixtures with $\mathrm{CH}_{4}$ and $\mathrm{H}_{2}$ are studied in well-controlled experimental conditions in an installation shown in figure 1.

This research is performed considering the effect of main variables: air excess ratio (from pyrolysis to highly oxidant conditions), pressure (1-60 bar)[5], temperature (400-800 K), concentration of $\mathrm{CH}_{4}$ and $\mathrm{H}_{2}$ in the mixture, and presence of pollutants such as NO.

In the experiments, concentrations of $\mathrm{NH}_{3}, \mathrm{CH}_{4}, \mathrm{H}_{2}$, $\mathrm{CO}, \mathrm{CO}_{2}$, hydrocarbons, $\mathrm{NO}, \mathrm{NO}_{2}, \mathrm{~N}_{2} \mathrm{O}$ and $\mathrm{HCN}$ will be analysed.

Experimental results will be simulated and interpreted with a detailed kinetic reaction model, that allows us to describe the ammonia combustion process under the differen operating conditions.

This mechanism will be progressively developed, updated and improved according to the experimental results obtained.

\section{Outcomes}

It is expected to obtain a series of data that will allow us to increase the quality and quantity of knowledge about the combustion of $\mathrm{NH}_{3}$ and its mixtures.

At the same time, developing a good predicting kinetic model, that allow us to design several simulation models with Chemkin and another multiphysics simulation softwares, obtaining a proper correlation among the experimental results, the kinetic model and simulation modelling.

\section{REFERENCIAS}

[1] A. Valera-Medina, H. Xiao, M. Owen-Jones, W.I.F. David, P.J. Bowen, Ammonia for power, Prog. Energy 
Combust. Sci. $69 \quad$ (2018) 63-102. https://doi.org/10.1016/j.pecs.2018.07.001.

[2] H. Kobayashi, Ammonia Combustion for Energy System, Japan-Norw. Hydrog. Semin. (2017). http://injapan.no/wp-content/uploads/2017/02/13-Prof.Kobayashi-Ammonia-Combustion.pdf

[3] P. Glarborg, J.A. Miller, B. Ruscic, S.J. Klippenstein, Modeling nitrogen chemistry in combustion, Prog. Energy Combust. Sci. 67 (2018) 31-68. https://doi.org/10.1016/j.pecs.2018.01.002.
[4]

R. Li, A.A. Konnov, G. He, F. Qin, D. Zhang, Chemical mechanism development and reduction for combustion of $\mathrm{NH}_{3} / \mathrm{H}_{2} / \mathrm{CH}_{4}$ mixtures, Fuel. 257 (2019) 116059. https://doi.org/10.1016/j.fuel.2019.116059.

[5] Y. Song, H. Hashemi, J.M. Christensen, C. Zou, P. Marshall, P. Glarborg, Ammonia oxidation at high pressure and intermediate temperatures, Fuel. 181 (2016) 358-365.

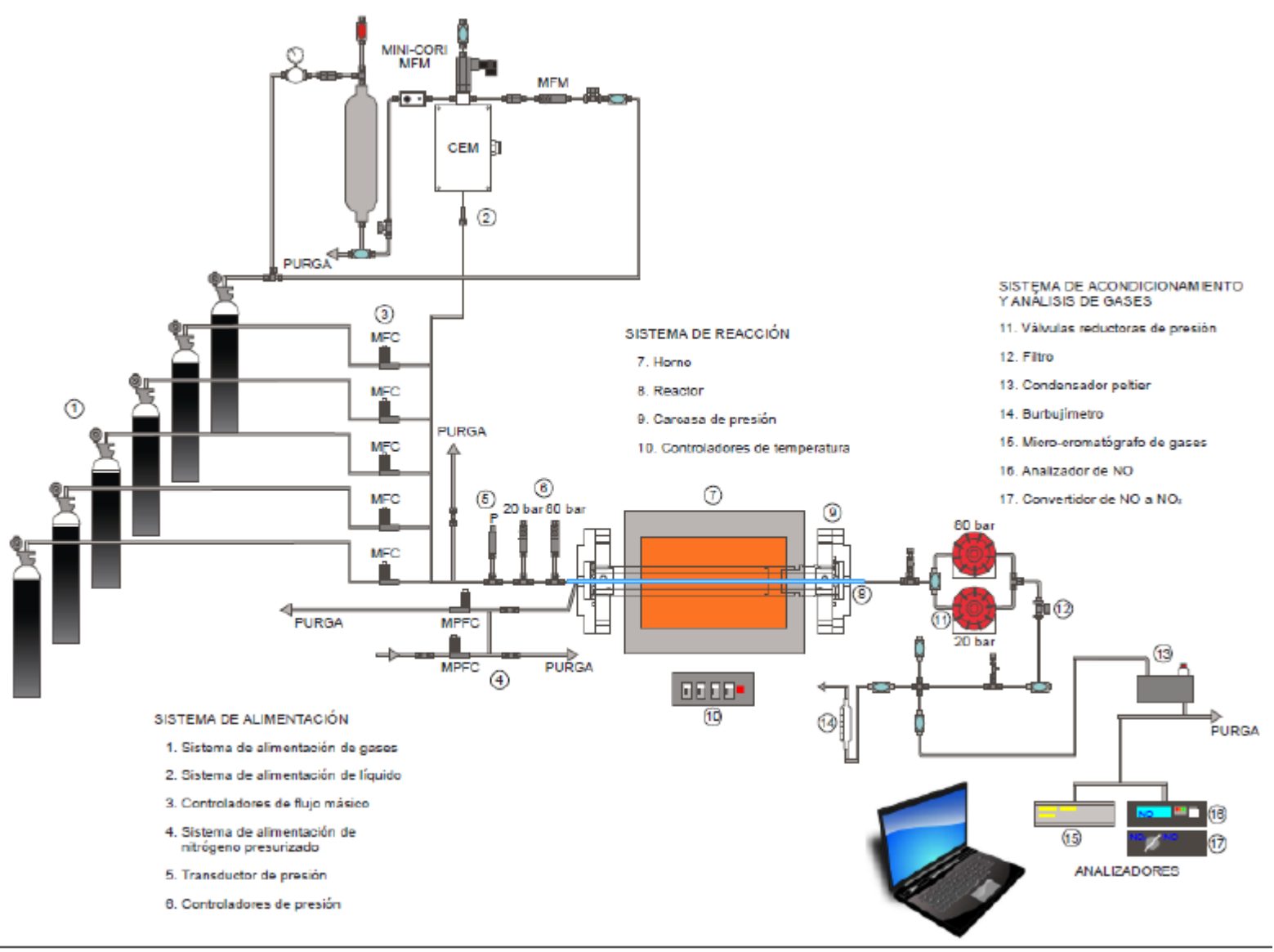

Figura 1: High pressure installation 